\title{
Natural variability of summer rainfall over China in HadCM3
}

\author{
Yonghui Lei $\cdot$ Brian Hoskins $\cdot$ Julia Slingo
}

Received: 24 August 2012/ Accepted: 6 March 2013/Published online: 26 March 2013

(C) The Author(s) 2013. This article is published with open access at Springerlink.com

\begin{abstract}
Summer rainfall over China has shown decadal variability in the past half century, which has resulted in major north-south shifts in rainfall with important implications for flooding and water resource management. This study has demonstrated how multi-century climate model simulations can be used to explore interdecadal natural variability in the climate system in order to address important questions around recent changes in Chinese summer rainfall, and whether or not anthropogenic climate change is playing a role. Using a 1,000-year simulation of HadCM3 with constant pre-industrial external forcing, the dominant modes of total and interdecadal natural variability in Chinese summer rainfall have been analysed. It has been shown that these modes are comparable in magnitude and in temporal and spatial characteristics to those observed in the latter part of the twentieth century. However, despite 1,000 years of model simulation it has not been possible to demonstrate that these modes are related to similar variations in the global circulation and surface temperature forcing occurring during the latter half of the
\end{abstract}

\section{Y. Lei $(\bowtie)$}

State Key Laboratory of Remote Sensing Science, Institute of Remote Sensing and Digital Earth, Chinese Academy of Sciences, Beijing, China

e-mail: yonghui.lei@hotmail.com

Y. Lei · B. Hoskins - J. Slingo

Department of Meteorology, Walker Institute,

University of Reading, Reading, UK

\section{B. Hoskins}

Grantham Institute, Imperial College, London, UK

J. Slingo

Met Office, Exeter, UK twentieth century. This may be in part due to model biases. Consequently, recent changes in the spatial distribution of Chinese summer rainfall cannot be attributed solely to natural variability, nor has it been possible to eliminate the likelihood that anthropogenic climate change has been the driving factor. It is more likely that both play a role.

Keywords Natural variability - Decadal timescales . Summer monsoon rainfall $\cdot$ HadCM3

\section{Introduction}

There is mounting evidence that the summer rainfall over China and the broader East Asian summer monsoon (EASM) have exhibited substantial variability on long timescales, exceeding a decade or more. A variety of proxy climate data have been used to characterize the precipitation and prevailing climate over China from millennia to hundreds of millennia (e.g., Wang et al. 2008). Proxy records are sparse spatially, but they reveal decade-tocentury-scale variability that is not obviously related to factors such as variations in the earth's orbit and obliquity, or volcanic activity. In-situ based measurement indicates that interdecadal variability in summer rainfall over China in the last 50 years to a century has distinctive spatial and temporal structures (e.g., Ding et al. 2008). Although instrumental records are known to be insufficient for a proper estimation of internal variability on long timescales, the observational study by Lei et al. (2011, hereafter LHS) suggests that natural variability may be a determining factor in recent trends in Chinese rainfall. Also, the observational evidence suggests that both natural variability and anthropogenic climate change impact on Chinese summer rainfall, associated with changes in the regional 
atmospheric circulation and hydrological cycle (e.g., Zhou et al. 2008; LHS).

Knowledge of the internal variability of precipitation is currently lacking, but it is critical for climate change detection and attribution studies. Atmosphere-ocean coupled general circulation models (AOGCMs) have been widely employed to investigate climate variability and change (e.g., Lambert et al. 2005; Held and Soden 2006). With constant external forcing in control simulations of AOGCMs, internal processes involving the atmosphere, the ocean, the large ice sheets and other components of the climate system lead to internal climate variability on wide range of time scales (Hasselmann 1976). Studies of internal variability on annual to decadal time-scales require simulation lengths of order a 1,000 years. Several control integrations of more than 1,000 years, have already been analyzed to investigate the natural variability in near-surface temperature (e.g. Stouffer et al. 2000; Braganza et al. 2002) and various atmospheric and oceanic variables (e.g. von Storch et al. 2001; Monahan and Dai 2004). It is worth noting that some of AOGCMs require annual mean flux adjustment in order capture a stable, long-term mean climate without significant climate drift. HadCM3, the model used in this study is one of those that no longer require flux adjustment.

The internal variability in precipitation in millennial simulations has rarely been considered, partly because the simulation of the large-scale spatial patterns and temporal variation of precipitation is still a big challenge for AOGCMs. Various climate models are in broad agreement about global warming and the general increase in heavy daily rainfall events in the twentieth century simulations, but there is little agreement about precipitation variability at a regional level. For example Dai (2006), using multimodels that participated in the IPCC 4th assessment report (AR4), found a broad similarity in the mean global precipitation distribution and interannual variability to that observed, but noted a tendency for an unrealistic doubleITCZ over the tropical Pacific, as well as too strong a coupling of tropical convection to local sea surface temperatures (SSTs) which may be in error. These common problems in AOGCMs have large impacts on for instance the precipitation over the Asian monsoon region (Boo et al. 2011), although the Met Office Hadley Centre coupled model, HadCM3, was found to be one of few AOGCMs that is able to capture quite realistic decadal variability in the East Asian monsoon in its twentieth century simulation (Zhou and Dai 2007).

Due to paucity of observations in some parts of the world, there is large uncertainty in regional precipitation changes associated with changes in regional weather patterns as the planet warms (IPCC 2007). Over China, observations based on historical in situ measurements show that large regional changes have occurred in the total rainfall amount, as well as in the intensity and frequency of daily precipitation (Zhai et al. 2005, LHS). These could be in response to increases in greenhouse gases and hence a warming climate or to aerosols (Hu 1997; Menson et al. 2002). However, precipitation changes are also associated with patterns of natural variability in the climate system. For example, El Niño and the North Atlantic Oscillation (NAO) have substantial influence on precipitation on regional and global scales (e.g., Trenberth and Hurrell 1994; Slingo and Annamalai 2000; Yu and Zhou 2004). Wang et al. (1981) found a dominant quasi-80-year variability based on a reconstruction of the summer rainfall record for the last 500 years in China. More recent studies (Ding et al. 2007; Gong and Ho 2002; Zhu and Wang 2002) have commented that weakening of the East Asian summer monsoon since the late 1970s and associated pattern of south flooding and north drought may be one phase of the 80-year oscillation.

The principal aims of this work are to analyze the internal variability of Chinese summer rainfall in the HadCM3 1,000-year control simulation, and to consider the evidence that the marked variations observed in Chinese summer rainfall during 1958-2008 could be consistent with natural variability in the climate system. HadCM3 has been shown to have a stable climate state in 1,000-year integrations with constant external forcing and without flux adjustments. Collins et al. (2001) investigated the internal variability in surface temperature of the 1,000-year integration of HadCM3, and concluded that for this variable the internal variability of HadCM3 is generally consistent with the observations on annual to interdecadal time scales. In particular, the model can simulate an El Niño Southern Oscillation (ENSO) with an irregular 3-4 year period and spatial patterns of interdecadal variability of SST in the tropical Pacific, North Pacific and North Atlantic Oceans that resemble observations. This raises the question whether the model also has the ability to reproduce the observed characteristics of internal variability in precipitation. Over China, summer rainfall is likely impacted by global sea surface temperature modes like ENSO and Pacific Decadal Oscillation (PDO; Lau and Weng 2001; Wang et al. 2012).

\section{Data and methods}

HadCM3 is a version of the UK Meteorological Office Unified Model and one of the AOGCMs participating in IPCC AR4. Its standard form uses a $3.75^{\circ} \times 2.5^{\circ}$ longitude-latitude grid with 19 hybrid vertical levels in its atmospheric component; and $1.25^{\circ} \times 1.25^{\circ}$ longitude-latitude grid with 20 vertical levels in its oceanic component. 
Although HadCM3 has been used for a decade and subsequent developments in model formulation (such as higher resolution) have been made, it is still considered to be a competitive model that represents important aspects of the current climate including the mean climate and its variability (IPCC 2007). More details of the model's formulation and performance can be found in Pope et al. (2000) and Gordon et al. (2000), which focus on the atmospheric and oceanic components respectively.

Without flux adjustments, HadCM3 gives a stable mean state in the 1,000-year control simulation in which all concentrations of greenhouse gases and aerosols are set as constants representative of the pre-industrial era; the solar constant is also fixed. Details of the integration are given in Collins et al. (2001). Using this 1,000-year control simulation, the internal variability in the summer rainfall over China will be examined in this paper.

For comparisons with observations, a number of data sources will be used: the climate prediction centre merged analysis precipitation (CMAP) from 1979 to 2007; the observed monthly precipitation over China from 1958 to 2008 provided by the China Meteorological Administration (CMA); and large-scale variables (surface atmosphere temperature, $850 \mathrm{hPa}$ wind, $200 \mathrm{hPa}$ geopotential height and preciptation) from 1958 to 2002 in the reanalysis data (ERA40) provided by the European Centre for MediumRange Weather Forecasts. These observations and reanalyses are all interpolated onto the HadCM3 grid. The focus will be on the period 1958-2008 as covered by the CMA data, and analysed in LHS.

It should be noted that observational records are affected by external forcings (e.g. volcanic eruptions, changes in solar output as well as the anthropogenic emissions of greenhouse gases, sulphate aerosols, and ozone depleting gases; Stouffer et al. 2000), whereas HadCM3 uses constant pre-industrial forcing. Consequently the different external forcing may cause differences in Chinese summer rainfall compared with observed, in both climatology and variability.

\section{Climatology}

June-August is the rainy season with prevailing low-level southerly winds over the East Asian region (Tao and Chen 1987). Figure 1 shows the seasonal mean precipitation and lower tropospheric circulation depicted by the $850 \mathrm{hPa}$ streamfunction over Asia and the surrounding oceans, together with $200 \mathrm{hPa}$ eddy geopotential height (Z200), in the 1,000-year control simulation of HadCM3 and those observed. Consistent with the mean of the twentieth century climate simulation of HadCM3 (Johns et al. 2003) and other models shown in IPCC AR4, the climatology of precipitation and large-scale circulation in the 1,000-year control simulation (Fig. 1a) is generally similar to those in observations and reanalyses (Fig. 1b). During the boreal summer in both the simulation and observation, intense precipitation is associated with the ITCZ that occurs over the west Pacific. A second branch of heavy rainfall is found in South Asia monsoon regions, influenced by the flow from the Indian Ocean region and the North Pacific subtropical anti-cyclonic circulation.

Differences from the observation and reanalyses show that HadCM3 simulated more precipitation over East Asia and a stronger subtropical anti-cyclone over north-west Pacific which extends further south and west than observed (Fig. 1c). Precipitation biases over East Asia can be physically linked with the model biases in the tropics, such as the double ITCZ and the westwards extension of the equatorial Pacific cold tongue. These typically lead to too much rainfall over the Maritime continent, South Asia and Philippine Sea, together with dry biases in the Indian and Pacific Oceans near the equator and the Bay of Bengal. As a result, the associated circulation biases are relatively large in the tropical Pacific and along the coast of Asia into the mid and high latitudes, known as the Pacific-Japan (PJ) pattern.

Nitta (1987) first identified the PJ pattern, which describes a Rossby wave-train extending from the Philippines to Japan. This wave-train is typically driven by heating in the deep tropics, where the upper level divergence from deep convection interacts with the sub-tropical jet. It is clear from Fig. 1 that the response of the upper tropospheric circulation (described by the $200 \mathrm{hPa}$ eddy geopotential heights) to tropical heating differs between HadCM3 and the ERA-40 reanalyses. The negative bias in precipitation east of the Philippines and positive bias south of Japan could be considered as evidence of a bias in the representation of the PJ pattern.

Although the large-scale upper tropospheric circulation patterns are similar (Fig. 1d, e), with anticyclones over the Tibetan Plateau and the midlatitude Eurasian continent, the difference (Fig. 1f) highlights an anomalous wave-train with centres located around the Philippines, Japan and East Siberia. This tripole pattern is similar to the climate anomaly pattern that dominates variations in the EASM (Hirota et al. 2005) and essentially describes changes in the position and strength of the North Pacific anticyclone and the subtropical jet. Hirota and Takahashi (2012) argue further that the moist processes associated with changes in the precipitation distribution act to strengthen the circulation anomalies.

Figure 2 shows the mean of precipitation over China and $850 \mathrm{hPa}$ wind for the months from June to August in the 1,000-year control simulation, and from observations and reanalyses. There is overall similarity, but the seasonal evolution in observations shows a large shift in rainfall 

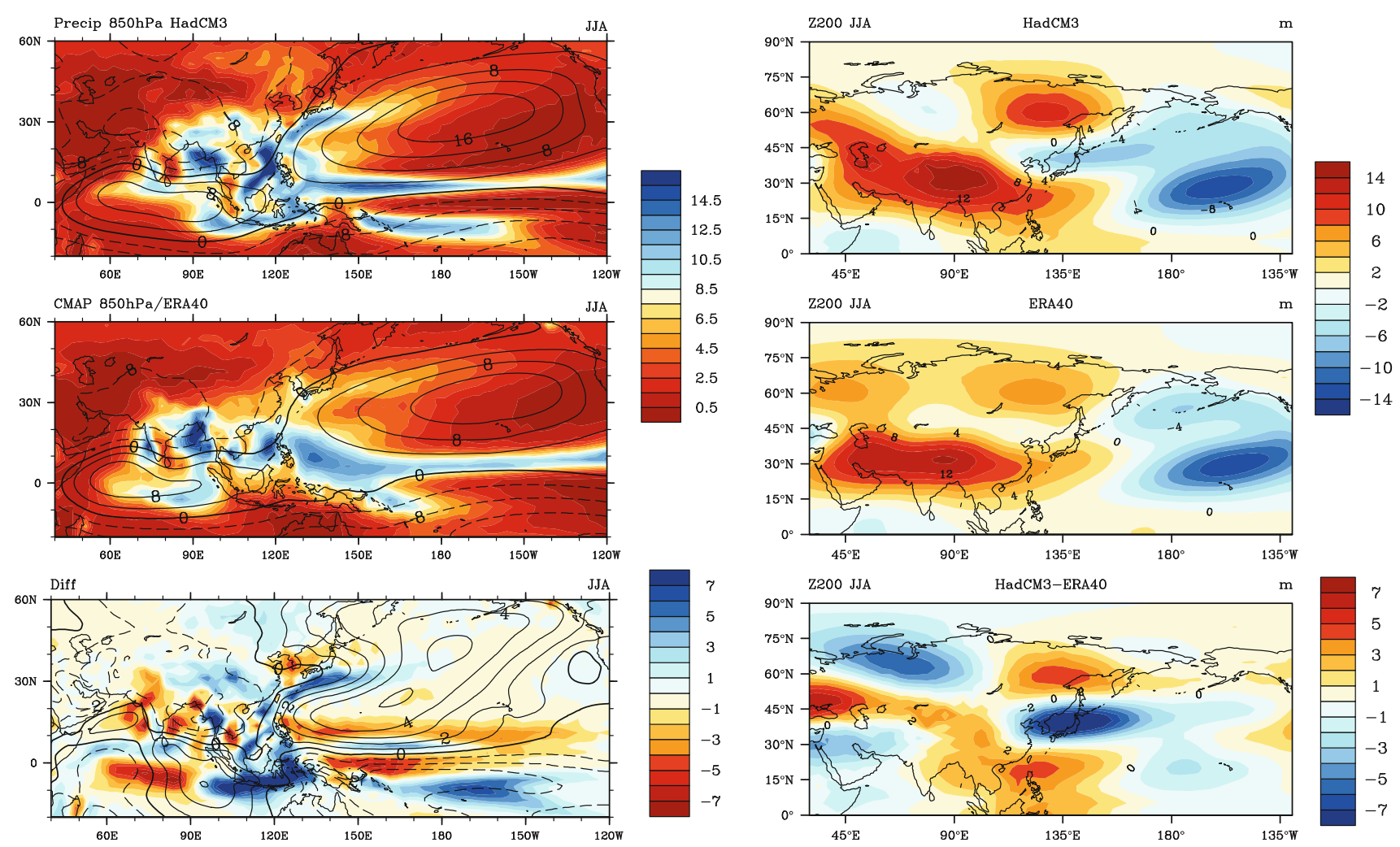

Fig. 1 Summer mean precipitation (mm/day) and $850 \mathrm{hPa}$ streamfunction $\left(10^{6} \mathrm{~m}^{2} \mathrm{~s}^{-1}\right)$, together with $200 \mathrm{hPa}$ geopotential height deviations from the zonal mean. $\mathbf{a}$ and $\mathbf{d}$ the 1,000 year control run of

HadCM3; (b and e) observed, CMAP precipitation and ERA-40; (c and f) the differences, model minus observed

northwards over East China from June to July, associated with the Mei-Yu Front, and then a withdrawal to the south in August, accompanied in turn by a northward penetration and then weakening of the southerly wind. The model does not really capture this behaviour. The main characteristic of the difference for each month is the generally wet bias over China. However, dry biases occurring over the lower reaches of the Yangtze River valley in June, over the Yellow River valley in July and August indicate less latitudinal movement of monsoon rainfall in the simulation. Associated with these local dry biases in the model, cyclonic circulation biases in the low-level atmosphere exist over the surrounding subtropical ocean area. Together with anticyclonic cells over the tropical northwest Pacific and the north of Japan, there are indications of a wave-pattern along the East Asian coast during summer, consistent with Fig. 1c. As noted above, the wave-like pattern with its divergence and dry biases over East China may be associated with the wet bias over the Maritime Continent and Philippines.

\section{Natural variability in Chinese summer rainfall}

Because the climates are so different in different parts of China (e.g., Ding and Sikka 2006), six geographic regions

have been analysed separately in the 1,000-year model run and in observations for the period 1958-2008. Table 1 summarizes the area-averaged mean and standard deviation of summer rainfall over all China and over the northeast, the Yellow and Yangtze River valleys, the southeast, the southwest and northwest China. Consistent with Fig. 2, the mean summer rainfall in the model is significantly larger than observed over all the areas studied, except the southeast.

The variability in the regional summer rainfall can be divided into two components, the 11-year running mean to represent decadal and longer timescales, and the residual, high-frequency (interannual) component. As indicated by Table 1, there is no consistent over or under-estimate of variability in the model. In both the simulation and observations, the standard deviations on decadal time scales are generally smaller than those on interannual timescales. The ratios of the two timescales in the model and in the observations are quite similar, about 0.3 and 0.4 , respectively. However, in the northeast and southeast, the decadal variability is too small, whereas in the Yellow River valley it is too large. In the Yangtze River valley and west China, the interannual variability is too large. For the whole of China, the simulated interannual variability is comparable to that observed, while the simulated decadal variability is underestimated. 

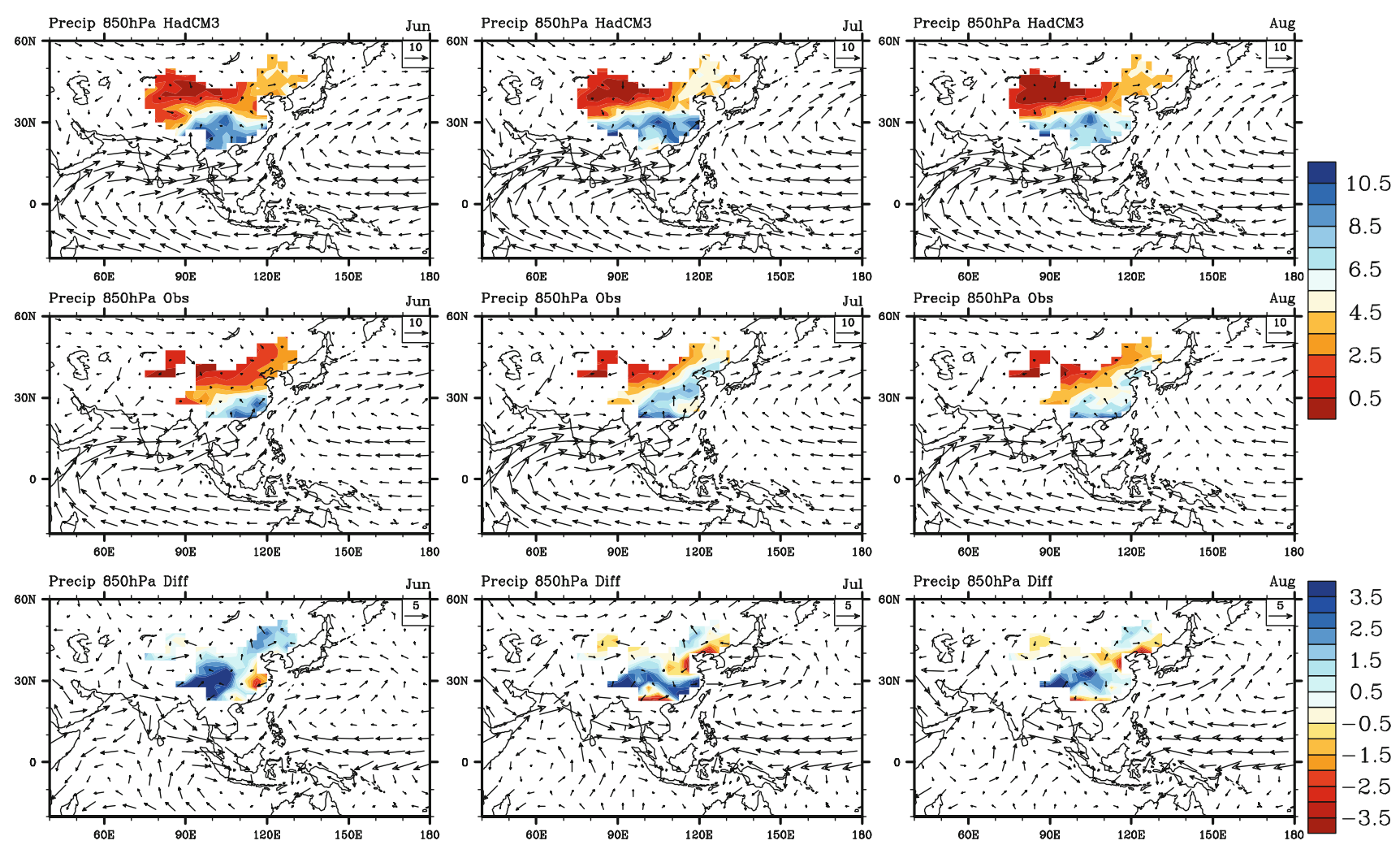

Fig. 2 Monthly mean precipitation (mm/day) over China only and $850 \mathrm{hPa}$ wind (m/s) from June to August (left to right) for the 1000 year control run of HadCM3 (top), observed using rain gauge data and ERA-40 (mid), and differences (bottom)

Table 1 Mean and standard deviations of summer rainfall over specified regions for the HadCM3 simulation and for 51-years of rain gauge data

\begin{tabular}{lllllll}
\hline Domains & \multicolumn{5}{l}{ Simulation and observations } \\
\cline { 2 - 7 } & Mean & \multicolumn{5}{l}{ Standard deviations } \\
\cline { 3 - 7 } & & \multicolumn{5}{l}{ Interannual } \\
\end{tabular}

The units are $\mathrm{mm} /$ day and the standard deviations are shown for both interannual and decadal time-scales. Using statistic $t$ test, significantly differences in model results compared with observations are indicated in bold (positive) and italics (negative). The defined domains include China, the northeast (north of $45^{\circ} \mathrm{N}$ and east of $105^{\circ} \mathrm{E}$ ), the Yellow River Valley $\left(35^{\circ} \mathrm{N}-42.5^{\circ} \mathrm{N}\right.$ and east of $\left.105^{\circ} \mathrm{E}\right)$, the Yangtze River valley $\left(27.5^{\circ} \mathrm{N}-32.5^{\circ} \mathrm{N}\right.$ and east of $105^{\circ} \mathrm{E}$ ), the southeast (south of $25^{\circ} \mathrm{N}$ and east of $105^{\circ} \mathrm{E}$ ), the southwest (south of $35^{\circ} \mathrm{N}$ and west of $101.25^{\circ} \mathrm{E}$ ) and northwest (north of $37.5^{\circ} \mathrm{N}$ and west of $101.25^{\circ} \mathrm{E}$ )

Dominant patterns of Chinese summer rainfall variability in the 1,000-year control simulation have been extracted using an empirical orthogonal function (EOF) analysis, applied to both the total and 11-year running average Chinese summer rainfall data from the 1,000-year control simulation. As expected from Table 1, the total data are dominated by interannual variability. The three leading spatial patterns of Chinese summer rainfall are shown in Fig. 3. The spatial structure and variances are similar with and without the decadal smoothing. According to the criterion of North et al. (1982), the leading three patterns for the raw data are significantly independent, and the leading two decadal patterns are statistically significant. The first EOF highlights a dipole structure between the Yangtze River valley and southern China, whereas the second EOF highlights a rainfall anomaly throughout southern China. The third pattern describes a tripole structure over eastern China.

The wavelet power spectra of the leading three principle components for the raw data are displayed in Fig. 3. Wavelet spectra for the 11-year smoothed PCs show similar behaviour on decadal time scales (figure not shown). The leading three patterns all exhibit large variability in periods 2-8 years, but different behaviour on longer timescales. The first and second modes both show large variability on the 16-32 year period, but active events occur at different times. The third mode has large variability at the 64-year period during years 500-700 of the model simulation. 

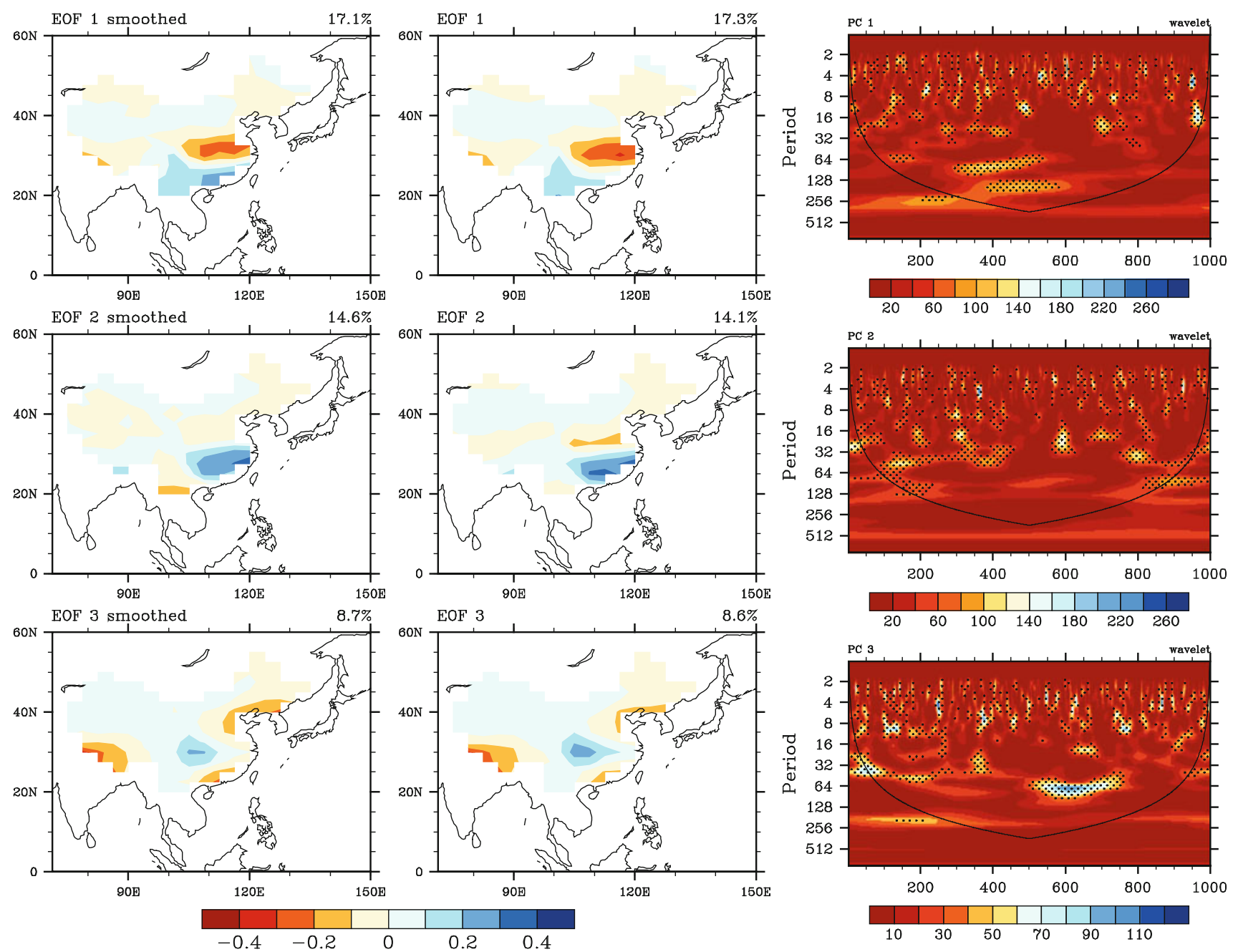

Fig. 3 The leading three EOFs of the low-pass filtered Chinese summer rainfall in the 1,000 year control simulation of HadCM3 (left), and the counterpart for the unfiltered data (mid). Wavelet

Based on time series of the leading three modes of summer rainfall over China, regressions of summer precipitation, $850 \mathrm{hPa}$ wind, Z200 and surface air temperature have been performed for the total and the low-pass filtered data, respectively. Overall the three dominant rainfall patterns over China show significant relationships with global large-scale variables. For the first mode, Fig. 4 shows that the dipole structure between the Yangtze and southern China is related to an elongated dry anomaly over south of Japan and to a wet anomaly over the South China Sea, as well as a dry anomaly over India. These rainfall anomalies are stable on for the total and interdecadal scales. Regressed large-scale atmospheric circulation and temperature anomalies are also similar, although amplitudes for the total data (interannual + interdecadal) are slightly larger. The dipole rainfall pattern over East Asia is associated with a lower-tropospheric anticyclonic anomaly over the Maritime continent and a cyclonic anomaly over analysis on the corresponding PCs of the unsmoothed data (right). Hatching indicates areas with the $5 \%$ significance level

the subtropical western Pacific, suggesting an eastwards migration of the Pacific sub-tropical anticyclone. As discussed by Huang and Sun (1994), enhanced convective activity over the West Pacific blocks moisture transport into the Yangtze River valley and causes the dry anomaly. In the upper troposphere, a tripole pattern is dominant from the subtropical western Pacific to south China and northeast Asia. These wave structures may be interpreted as Rossby waves that propagate northward in the lower troposphere and south-eastward in the upper troposphere (Hirota and Takahashi 2012).

Regressions of surface air temperature on to the first mode of rainfall variability (Fig. 4, bottom panels) highlight warm anomalies in the tropics over the Indian and West Pacific oceans, but cold anomalies over the northwest Pacific. The signal is much stronger on interannual timescales and is reminiscent of the SST pattern associated with the PDO. However, the colder than normal SSTs in the 
a

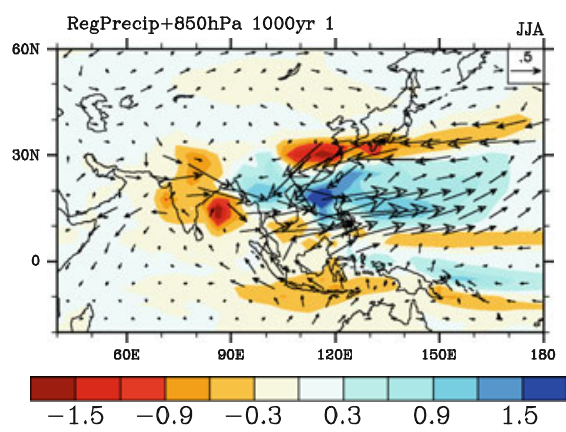

b
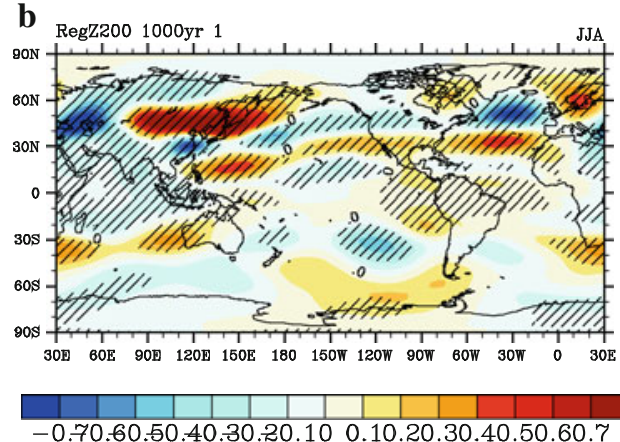

c

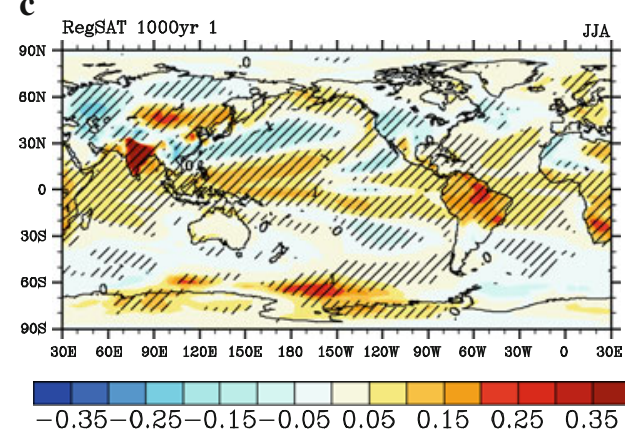

Fig. 4 Regressions of anomalies in model fields onto the PCs of the first EOFs of Chinese summer rainfall in the 1,000 year simulation (Left panel for the total data; the right for the low-pass filtered interdecadal data). Precipitation (colour shading) and $850 \mathrm{hPa}$ wind

equatorial east Pacific suggest a link to La Nina type conditions which is supported by the enhanced rainfall over the West Pacific and a weaker than normal Indian Summer Monsoon. There are also some coherent temperature anomalies over land which in summer are likely to be affected by rainfall anomalies, with enhanced soil moisture leading to more evaporation and hence land surface cooling; conversely, dry conditions lead to increased surface temperatures as evident over India in Fig. 4.

Figure 5 shows regressions for the second mode of rainfall variability with a wet anomaly over southern China. The rainfall anomaly over southeast China extends into the south of Japan, but is accompanied by different rainfall anomalies over the surrounding areas for the total data and interdecadal filtered data. Associated with different rainfall d
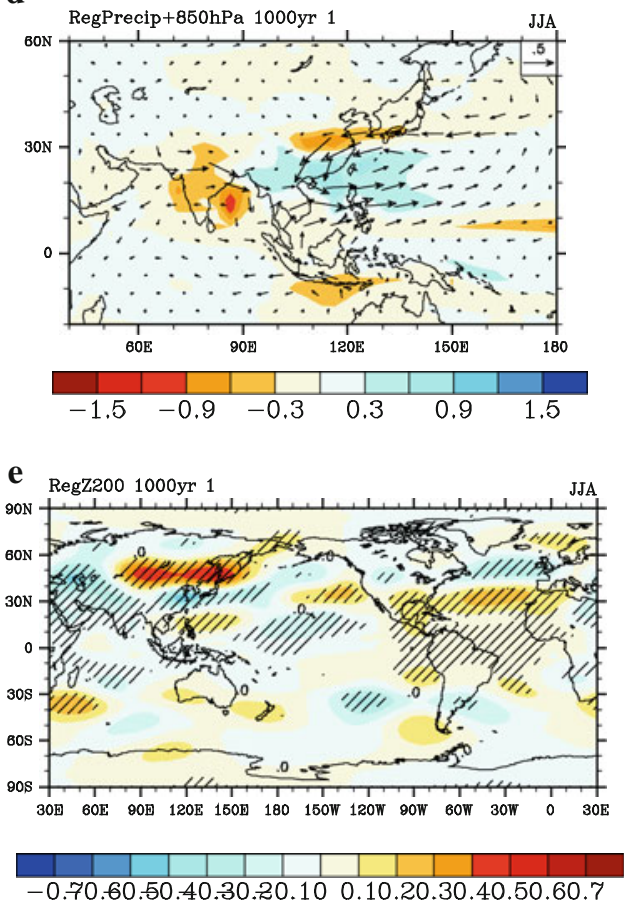

f

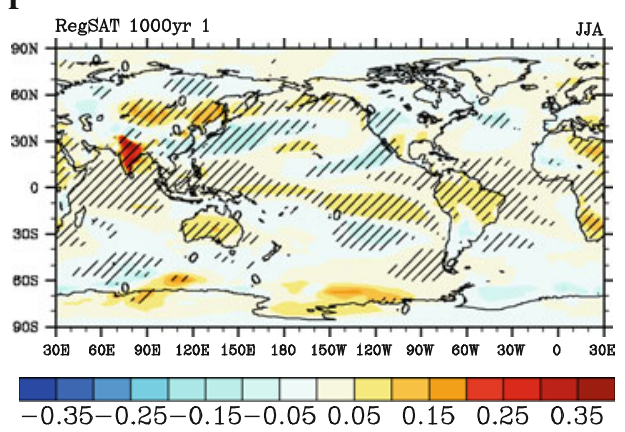

(vectors) in (a) and (d); $200 \mathrm{hPa}$ geopotential height deviations from zonal mean in (b and e) and surface air temperature in (c and $\mathbf{f})$ and, with hatching indicating areas with significance at the $5 \%$ level

anomaly patterns, regressed circulation patterns in the lower atmosphere also differ slightly although there is a consistent signal of an anomalous anticyclonic circulation in the subtropics, suggesting a westwards extension of the Pacific sub-tropical anticyclone and more moisture supply into southern China. Both timescales also show a cyclonic anomaly to the north, which, on interannual timescales, reinforces the rainfall anomaly over China. Regressions of Z200 for both the total and interdecadal timescales show similar tripole structures, but with less obvious connections to the deep tropics. Likewise, regressions of surface air temperature on both modes are weak and not indicative of strong forcing.

Finally, Fig. 6 shows regressions for the third mode which is characterized by tripole rainfall anomalies over 

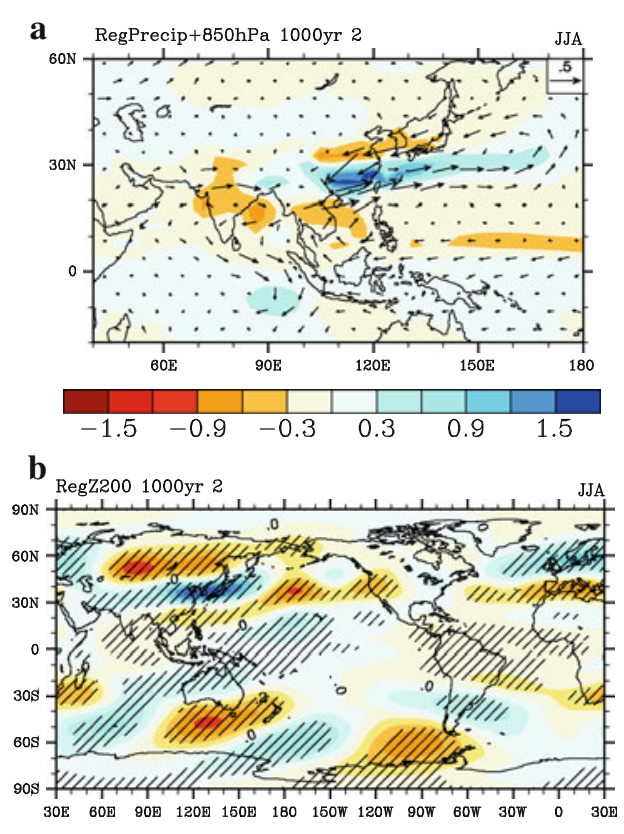

$-0.70 .60 .50 .40 .30 .20 .100 .10 .20 .30 .40 .50 .60 .7$

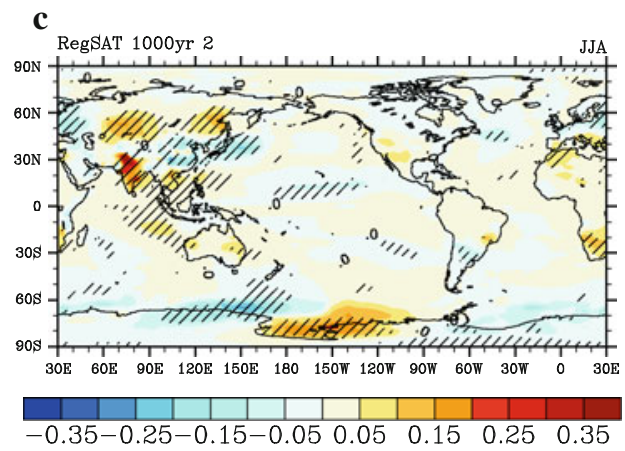

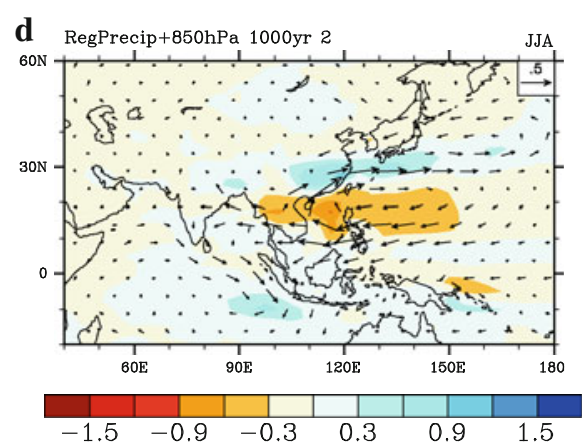

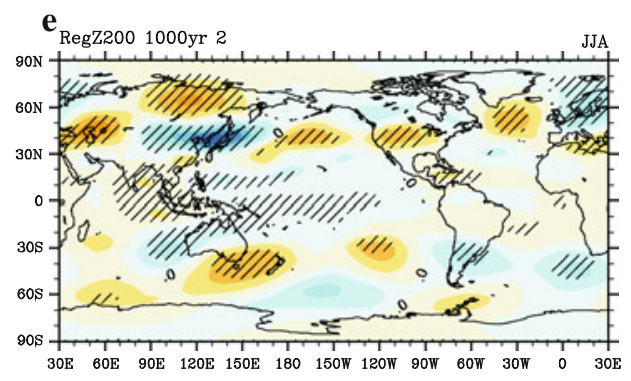

$-0.70 .60 .50 .40 .30 .20 .100 .10 .20 .30 .40 .50 .60 .7$

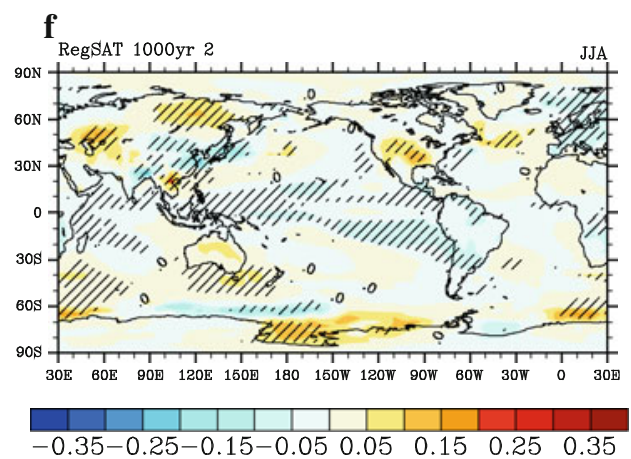

Fig. 5 Same as Fig. 4, but regressions with respect to the second EOFs of Chinese summer rainfall

east China. On both interannual and interdecadal timescales, the tripole rainfall pattern is accompanied by wet anomalies in the Maritime continent and south of Japan, as well as a dry anomaly over India. Regressed lower atmospheric circulation suggests that wet (dry) anomalies are consistent with confluence (diffluence) of the flow. For example, dry anomalies in the Yellow River valley and southeast China are associated with a cyclonic anomaly over the northwest Pacific. The regressed seasonal evolution from June to August (figure not shown) suggests that a closed cyclone occurring in the South China and Philippine Seas in June may be a response to tropical heating and that this shifts northwards in July and August. Regressions of Z200 are also similar on both timescales, with significant circulation anomalies in the upper troposphere globally. Regressed surface air temperature suggests a strong connection with El Niño and the PDO like patterns on interannual and interdecadal timescales.

\section{Comparison with observed decadal variability of summer rainfall over China}

Decadal variability of summer rainfall over China, determined using EOF analysis on low-pass filtered station observations in the period 1958-2008, is shown in Fig. 7. Here observational data are a gridded version based on the CMA station data and the HadCM3 grid. The EOFs and their PCs are very similar to those shown in LHS (Fig. 5) based on the raw station data. The leading mode describes large summer rainfall variability in southern China since the late 1970s, and the second mode describes interdecadal variability of Yangtze-Yellow rivers dipole in the last 51 years with a transition in the late 1970s.

The spatial correlations of the observed decadal variability of Chinese summer rainfall with the principle components of the three natural variability patterns in the 1,000-year HadCM3 control simulation are summarized in 

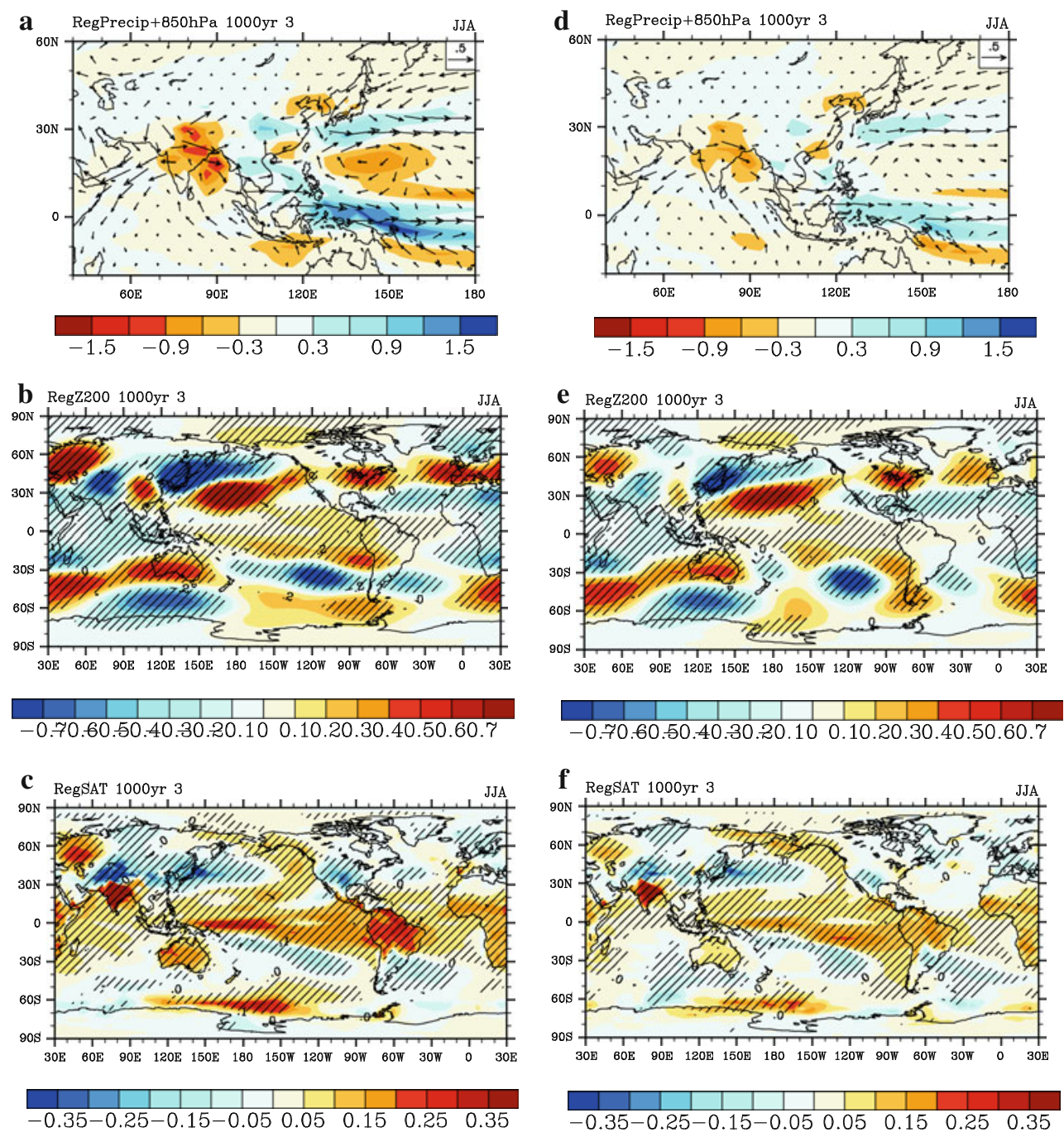

Fig. 6 Same as Fig. 4, but regressions with respect to the third EOFs of Chinese summer rainfall

Table 2. The leading three EOFs from the 1,000-year simulation, although similar in structure, cannot be directly linked to the individual observed EOFs. Bearing in mind that HadCM3 does not include changes in external forcing such as solar variability and anthropogenic greenhouse gases and aerosols, this is not surprising. However, the major result is that the first two EOFs project very strongly onto the space described by the first three model EOFs, with, respectively, 81 and $84 \%$ of the variance being described by them. This lends support to the hypothesis that observed changes in summer rainfall over China in the period 1958-2008 may have a contribution from natural variability.

One way to quantify the similarity is to calculate spatial and temporal correlations of observed decadal variability of summer rainfall over China (Fig. 7) with the counterparts during every 51-year running window in the HadCM3 1,000-year control simulation. Consequently, EOF analysis for the low-pass filtered Chinese summer rainfall is performed on every 51-year period of the simulation, and both the spatial and temporal correlations of the leading two EOFs are calculated with those from observations. Given significant spatial correlations (either positive or negative, at 0.01 significance level) of the leading two EOFs, the probability of finding dtwo similar patterns to those in the observed rainfall in a 51-year period of the 1,000-year simulation is $66.7 \%$. In accordance with significant temporal correlations and in-phase relations with corresponding spatial correlations, seven 51-year periods in the simulation are selected. Table 3 shows the centre years of the selected 51-year periods, as well as the corresponding spatial and temporal correlations of the leading two EOFs. Since selected samples are not independent when gaps between two samples are smaller than 50 years, only four independent 51-year periods in the simulation (centred at year of 292, 585, 727 and 913) are seen to show similar 

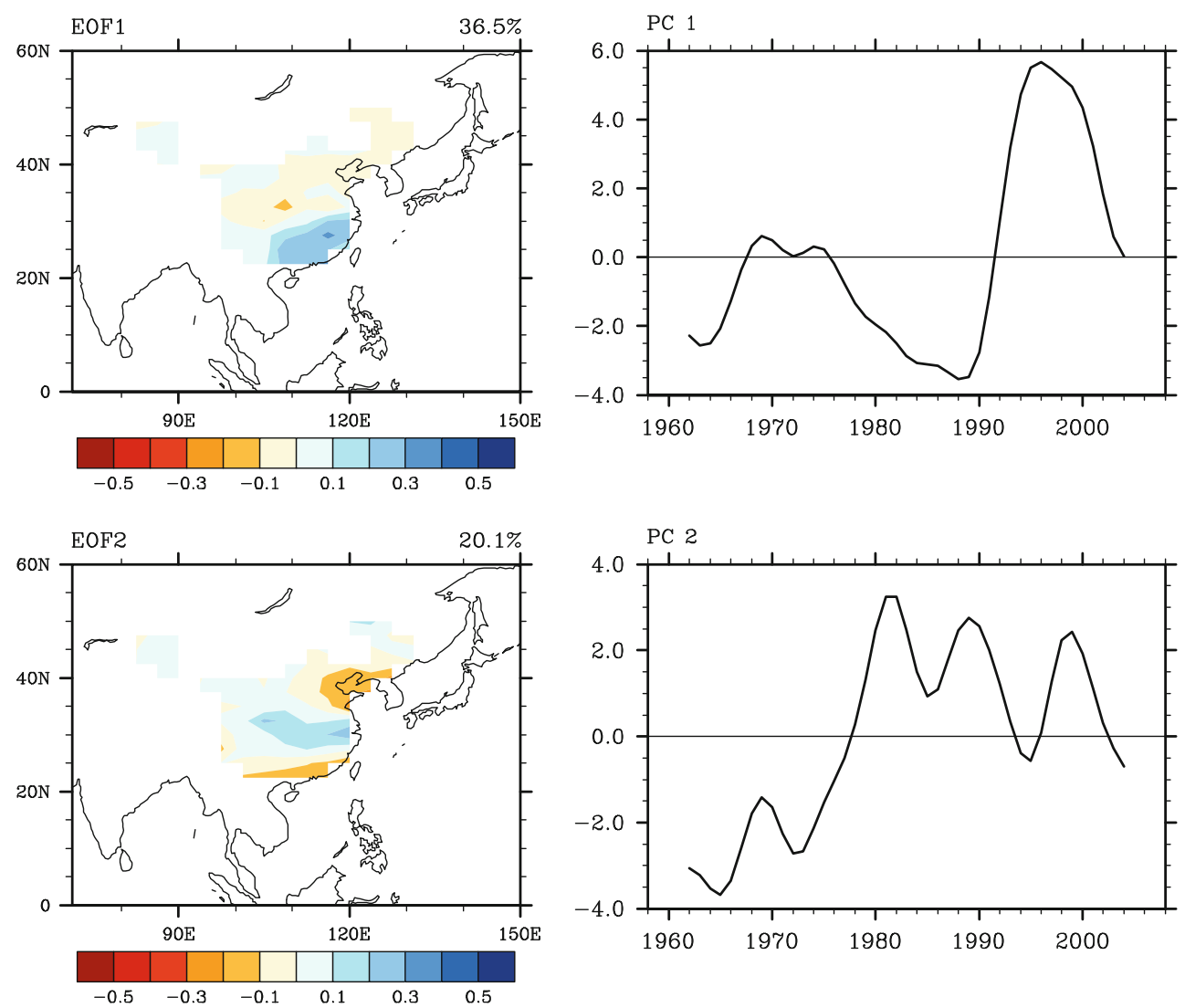

Fig. 7 The leading two EOFs (left) and corresponding PC (right) of observed low-pass filtered Chinese summer rainfall (mm/day) for the period 1958-2008. The station data have been interpolated onto the HadCM3 grids

Table 2 Spatial correlation coefficients of the leading two EOFs of observed interdecadal variability in Chinese summer rainfall in the last 51 years with the leading three EOFs in the 1,000-year HadCM3 control simulation

\begin{tabular}{|c|c|c|c|c|}
\hline \multicolumn{2}{|c|}{ Correlation coefficients } & \multicolumn{3}{|l|}{ Model } \\
\hline & & EOF1 & EOF2 & EOF3 \\
\hline & EOF1 & 0.54 & 0.70 & -0.16 \\
\hline \multicolumn{5}{|l|}{ Observations } \\
\hline & EOF2 & -0.54 & 0.41 & 0.62 \\
\hline
\end{tabular}

decadal variability of Chinese summer rainfall with observed.

Figure 8 shows the leading two EOFs of interdecadal variability and their PCs in low-pass filtered Chinese summer rainfall from the four independent 51-year periods in the control run. There is a strong similarity with the observed 51-year record in Fig. 7, as would be expected from the construction of the chosen periods. Comparisons of Figs. 7 and 8 show that large transitions from negative to positive states of the first EOF as observed in the 1990s and associated with drought over northern China, are also present in the model and therefore plausibly related to natural variability. Similarly the multi-decadal changes seen in the loading of the second EOF are also captured.

Given the similarity of the decadal variability in Chinese summer rainfall between the identified 51-year periods of the control run and that observed, it is of interest to compare associated precipitation, circulation and surface temperature anomalies. Figure 9 shows the regressed precipitation and $850 \mathrm{hPa}$ wind in summer on the time series of the leading two EOFs of decadal variability in Chinese summer rainfall in observations during the past 51 years, together with those from the four 51-year periods of the simulation. The key result from Fig. 9 is that despite the similarity in the distribution of rainfall anomalies over China between the model and the observations (Figs. 7 and 8 ), there is a wide diversity of broader scale precipitation and circulation anomalies in the model with none of the 51-year periods capturing the patterns seen in the observations. Likewise the regressed global surface temperature anomalies for each of the 51-year periods (Fig. 10) are also very diverse with a lack of common factors between the individual 51-year model scenarios and the observations.

In summary, although the model is capable of exhibiting large temporal transitions in the dominant modes of rainfall variability over China, just as has been observed, there is 
Table 3 Seven 51 year periods in the 1,000 year control run when spatial (rs) and temporal (rt) correlations of the leading two EOFs are statistically significant (at 0.01 significance level) with their counterparts in observations

\begin{tabular}{|c|c|c|c|c|c|}
\hline \multirow{2}{*}{$\begin{array}{l}\text { The central of } 51 \text {-year } \\
\text { periods in 1,000-years of HadCM3 }\end{array}$} & \multicolumn{2}{|c|}{ Correlations of EOF1 } & \multicolumn{2}{|c|}{ Correlations of EOF2 } & \multirow{2}{*}{$(\mathrm{rs} 1 * \mathrm{rt} 1) *(\mathrm{rs} 2 * \mathrm{rt} 2)$} \\
\hline & Spatial (rs1) & Temporal (rt1) & Spatial (rs2) & Temporal (rt2) & \\
\hline 292 & 0.79 & 0.4 & 0.55 & 0.43 & 0.07 \\
\hline 547 & -0.3 & -0.47 & 0.36 & 0.48 & 0.02 \\
\hline 585 & 0.72 & 0.46 & 0.59 & 0.74 & 0.15 \\
\hline 706 & 0.3 & 0.51 & 0.46 & 0.39 & 0.03 \\
\hline 727 & 0.56 & 0.44 & 0.48 & 0.7 & 0.08 \\
\hline 913 & 0.41 & 0.84 & 0.26 & 0.54 & 0.05 \\
\hline 917 & 0.37 & 0.77 & 0.28 & 0.5 & 0.04 \\
\hline
\end{tabular}

Four independent periods (centred at years 292, 585, 727 and 913) are marked in italicized

a
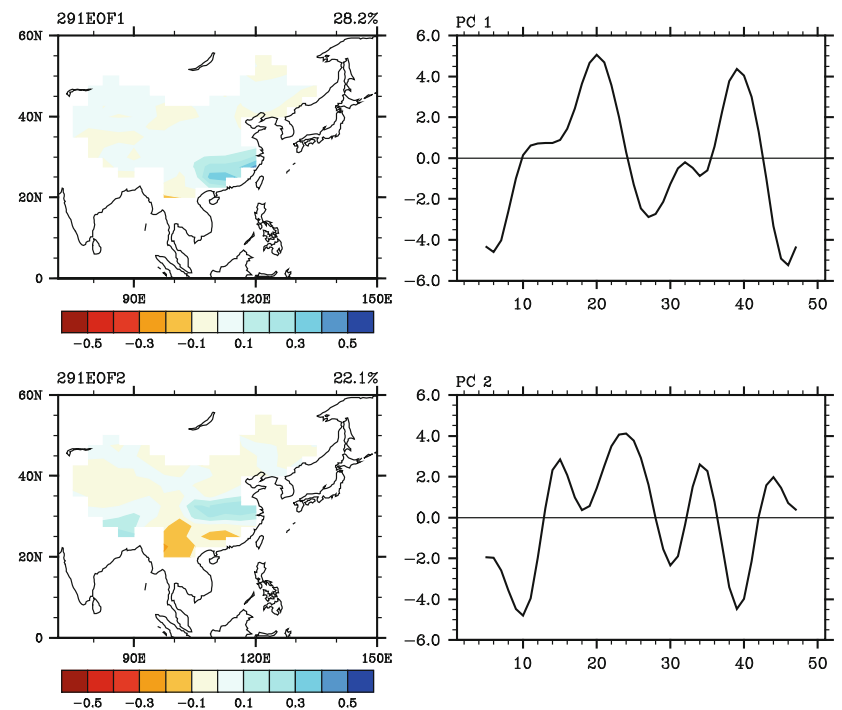

c
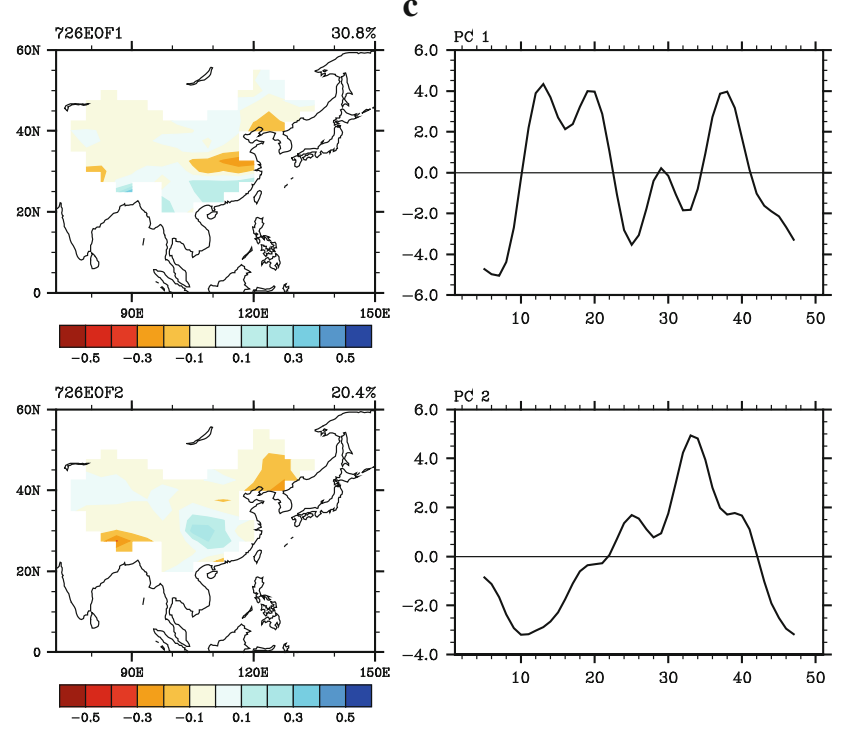

b
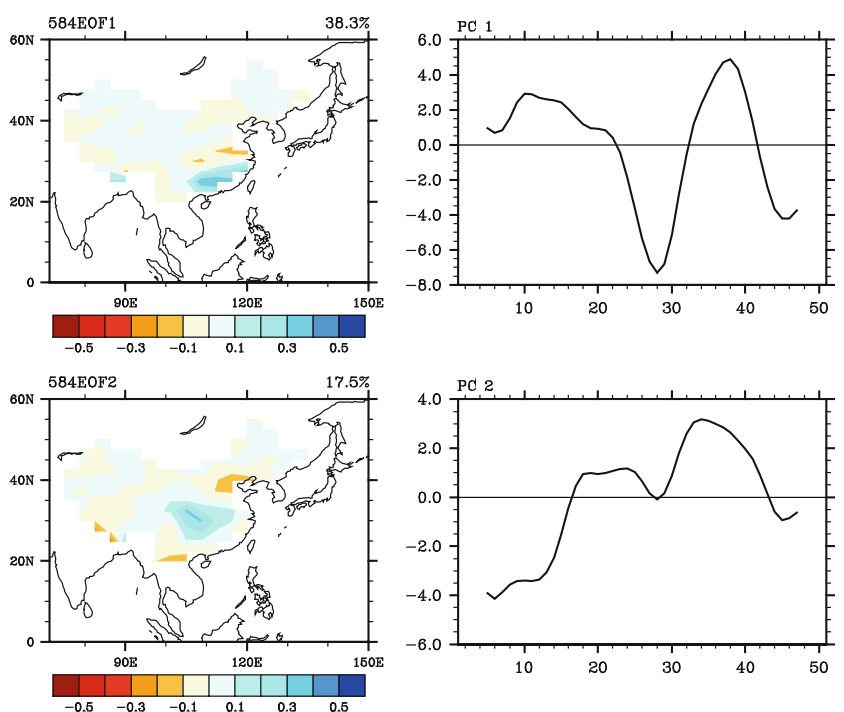

d
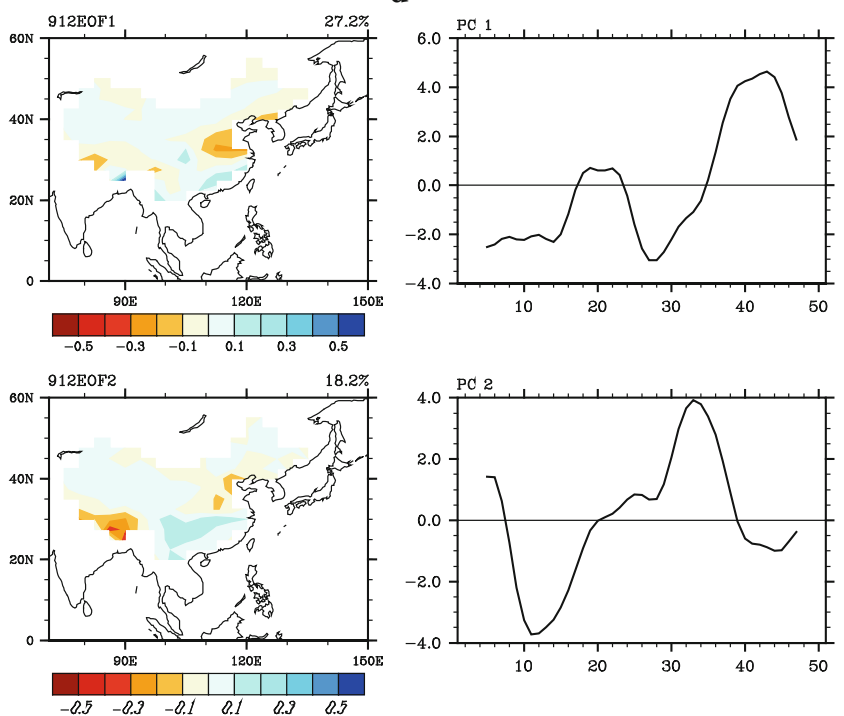

Fig. 8 The leading two EOFs and their PCs for low-pass filtered Chinese summer rainfall from four 51 year periods from HadCM3 centred at years $292(\mathbf{a}), 585(\mathbf{b}), 727(\mathbf{c})$ and $913(\mathbf{d})$ 
no consistency across the model events in terms of the regional and global scale surface temperature and circulation anomalies. Furthermore none of the identified 51-year periods in the model correspond with the observations for the recent past in terms of the associated regional and global scale patterns. It is not possible, therefore, to use the model results to support the hypothesis that recent variations in Chinese rainfall are due to natural, interdecadal variability. Nor can they be used to rule out the possibility that recent changes over China are due to the influence of anthropogenic climate change.

\section{Conclusions and discussion}

Natural climate variability in Chinese summer rainfall has been investigated using the data from a 1,000-year control simulation of HadCM3. After consideration of the model skill in simulating the mean climate and interannual variability, the focus has been on the natural, decadal variability in the model. A comparison with observed decadal variability in the period 1958-2008 has been performed to address the question of whether the marked interdecadal variability in observed Chinese summer rainfall over the last 51 years could be a product of natural, internal variability rather than attributable to global warming.

The mean climate of Chinese summer rainfall in the model used here has a generally realistic spatial distribution, but its evolution in the summer season is not so well simulated (Fig. 2). Model resolution can have an important impact on the simulation of the EASM (Kusunki et al. 2006; Gao et al. 2006; Boo et al. 2011) due to the spatial scale of the Meiyu Front. However, the bias over the Maritime Continent appears to be the dominant error in this coupled model (Fig. 1); the tropical heating bias leads to a quadrapole in tropical lower tropospheric circulation and a wave train along the coast of East Asia (Nitta 1987; Hirota and Takahashi 2012), consequently impacting on skill of the model over East Asia. Consistent with the twentieth century multi-model result reported by Dai (2006), the simulated mean summer rainfall over China in the control simulation is generally larger than in observations.

Nevertheless, the model is able to capture some important aspects of the observed variability in Chinese summer rainfall on interannual and decadal timescales. The ratio of decadal to interannual variability is about 0.3 in the model, compared with 0.4 in the last 51 years of observations and the dominant patterns of variability from EOF analysis for Chinese summer rainfall are similar to observations with and without decadal smoothing (Fig. 3). The leading interdecadal EOFs from the 1,000-year simulation, although similar in structure, cannot be directly linked to the individual observed EOFs. However, the two leading EOFs from the 51 years of observations do project very strongly on to the first three EOFs of the 1,000 years of the model, with respectively, 81 and $84 \%$ of the variance being described by them. This is very suggestive of a similarity in behaviour.

Based on this four independent 51-year periods (centred at model year of 292, 585, 727 and 913) in the 1,000-year control simulation are selected, as showing decadal variability in summer rainfall over China very similar to that observed with large temporal transitions in north-south distributions. However, regressed patterns of large-scale variables associated with decadal variability of summer rainfall over China indicate very different features in the model and observations (Figs. 9 and 10).

The evidence from the model has shown that even with constant external forcing, naturally occurring decadal variability leads to variations in the distribution of summer rainfall over China that is comparable to that observed in the latter part of the twentieth century. However, despite 1,000 years of simulation it was not possible to show that there are commonalities between the global environment in which the observed variations have occurred and those in the model. There are potentially three conclusions to be drawn from this result. Firstly, as already noted the model has some systematic biases, and these may preclude the generation of similar global patterns to those observed. Secondly, the diversity in the model 51-year periods may indicate that natural variability is itself very complex and that the lack of similarity between the model and the observations may just be a sampling problem. Thirdly, it may indeed be the case that the changes in external forcing in the real world due to greenhouse gases and aerosols are exerting an influence on Chinese summer rainfall. For example LHS has already shown that changes in the characteristics of daily rainfall, particularly the increasing intensity of heavy rain events, are consistent with global warming.

In conclusion, this study has demonstrated how multicentury model simulations can be used to explore interdecadal natural variability in the climate system in order to address important questions around recent changes in regional climate, specifically in Chinese summer rainfall, and whether or not anthropogenic climate change is playing a role. Such studies are important because the observational record is too short to identify with any certainty the potential links between regional variations and the global climate system especially on decadal and longer timescales. These simulations confirm that natural variability on decadal timescales can exist with comparable behaviour to that observed. However it has not been possible to show that recent changes in the spatial distribution of Chinese summer rainfall can be attributed solely to 

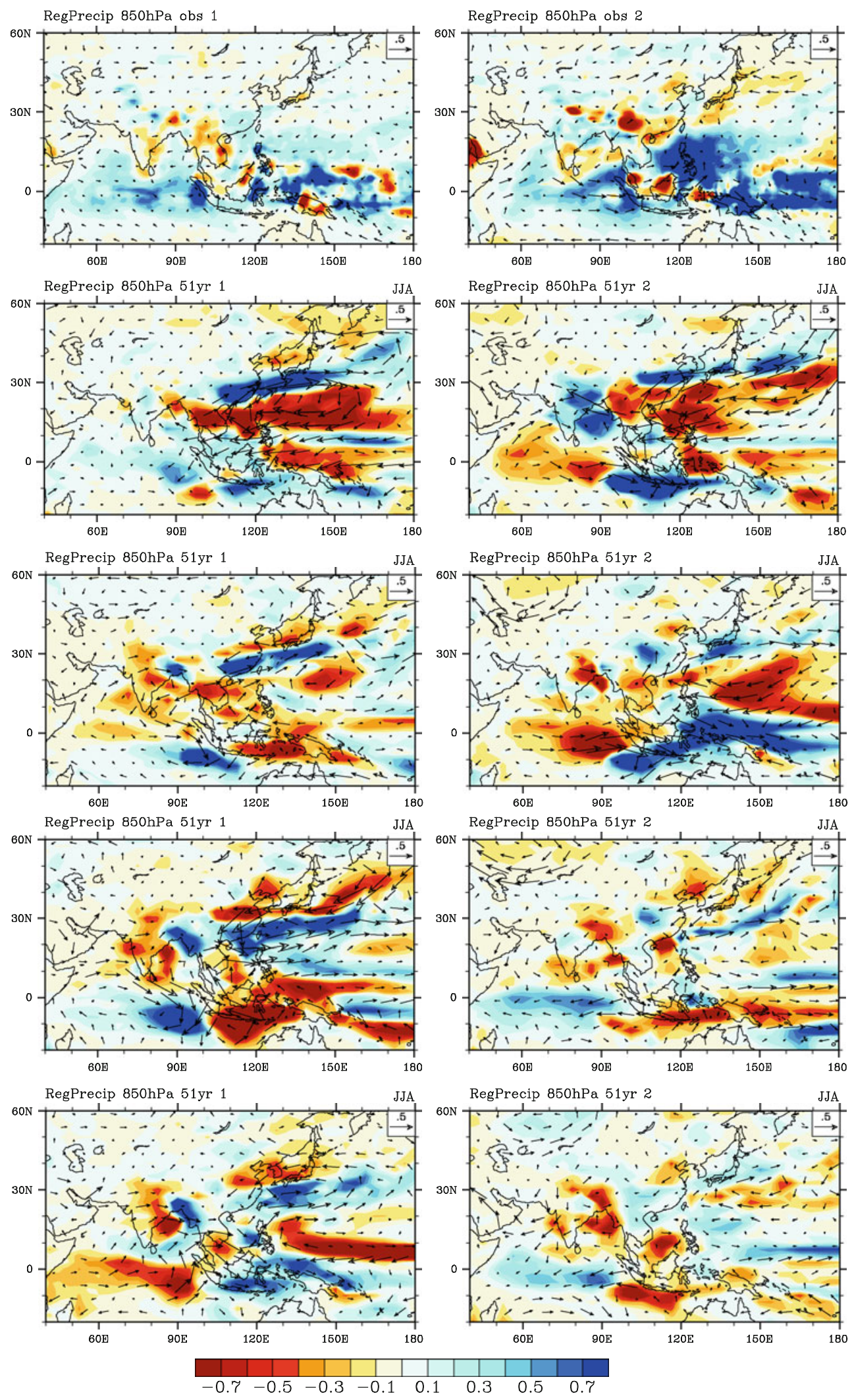

Fig. 9 Regressions of precipitation and $850 \mathrm{hPa}$ wind in summer on the time series of the leading two EOFs of decadal variability in Chinese summer rainfall in observations (top) and from the four 51 year periods from HadCM3 

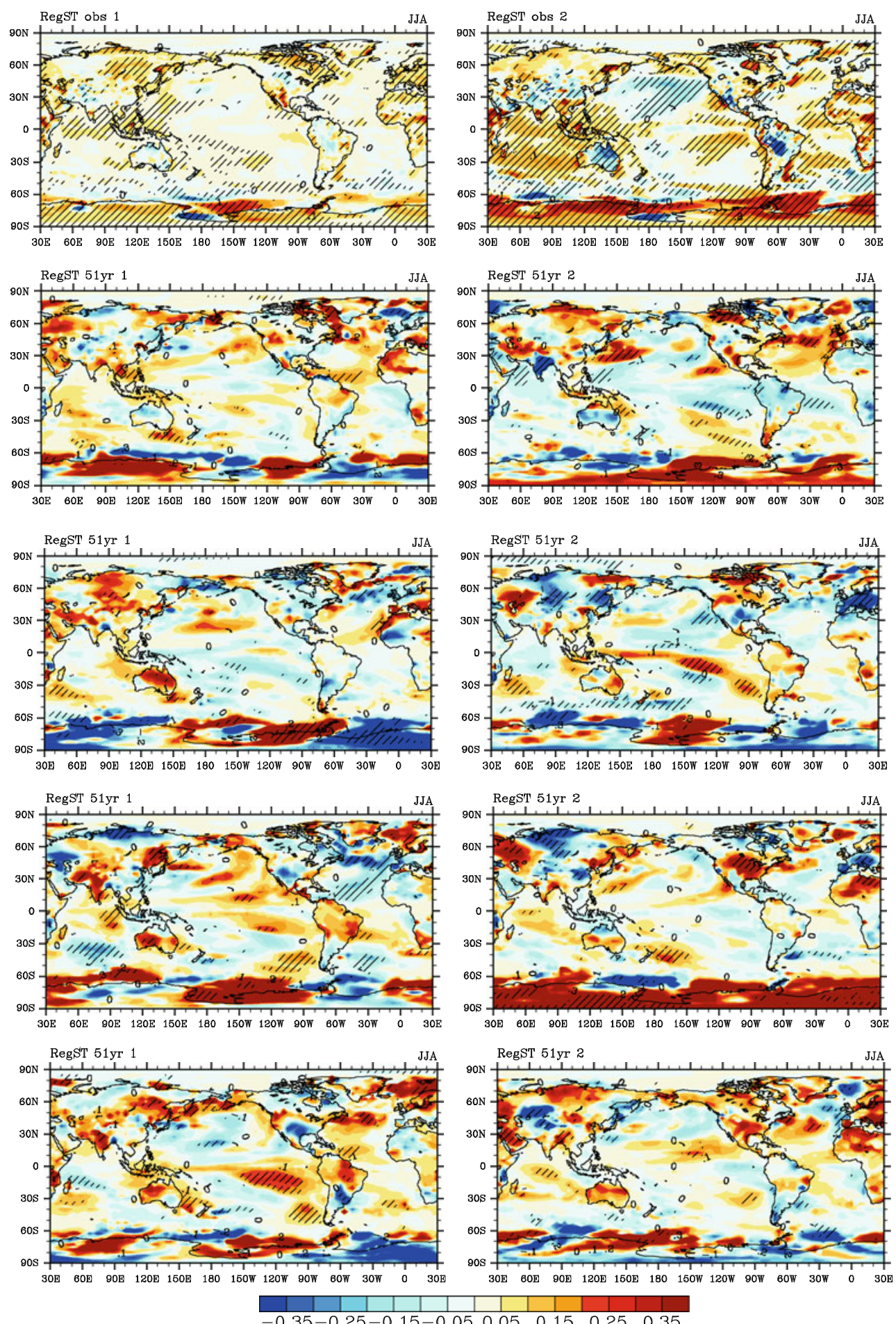

Fig. 10 Regressions of surface temperature in summer on the time series of the leading two EOFs of decadal variability in Chinese summer rainfall in observations (top) and the four 51 year periods in

natural variability, nor has it been possible to eliminate the likelihood that anthropogenic climate change has been the driving factor. It is likely that both play a role. As models
HadCM3. Hatching areas indicate significant regressions of surface temperature, with significance level at $10 \%$

continue to improve these questions need to be addressed again and placed in the context of model predictions for the coming decades. 
Acknowledgments This work was jointly supported by the CAS/ SAFEA International Partnership Program for Creative Research Teams (No. KZZD-EW-TZ-09) and the National Natural Science Foundation of China (Grant No. 40925015). Yonghui Lei was funded through a NERC Dorothy Hodgkin Award. Julia Slingo acknowledges the support of the NERC National Centre for Atmospheric Science.

Open Access This article is distributed under the terms of the Creative Commons Attribution License which permits any use, distribution, and reproduction in any medium, provided the original author(s) and the source are credited.

\section{References}

Boo K-O, Martin G, Sellar A, Senior C, Byun Y-H (2011) Evaluating the East Asian monsoon simulation in climate models. J Geophys Res 116:D01109. doi:10.1029/2010JD014737

Braganza K, Karoly DJ, Hirst AC, Mann ME, Stott P et al (2002) Simple indices of global climate variability a change: part Ivariability and correlation structure. Clim Dyn 20:491-502

Collins M, Tett S, Cooper C (2001) The internal climate variability of HadCM3, a version of the Hadley Centre coupled model without flux adjustments. Clim Dyn 17:61-81

Dai A (2006) Precipitation characteristics in eighteen coupled climate models. J Clim 19:4605-4630

Ding Y, Sikka DR (2006) Synoptic systems and weather. In: Wang B (ed) The Asian monsoon. Praxis Springer, Berlin, pp 131-201

Ding YH, Ren G, Zhao Z, Xu Y, Luo Y, Li Q, Zhang J (2007) Detection, causes and projection of climate change over China: an overview of recent progress. Adv Atmos Sci 6:954-971

Ding Y, Wang Z, Sun Y (2008) Inter-decadal variation of the summer precipitation in East China and its association with decreasing Asian summer monsoon. Part I: observed evidences. Int J Clim 28:1139-1161

Gao X, Xu Y, Zhao Z, Pal J, Giorgi F (2006) On the role of resolution and topography in the simulation of East Asian precipitation. Theor Appl Climatol 86:173-185

Gong D, Ho CH (2002) Shift in the summer rainfall over the Yangtze River valley in the late 1970s. Geophys Res Lett 29:1436. doi: 10.1029/2001GL014523

Gordon C, Cooper C, Seniro C, Banks H, Gregory J, Johns T, Miitchell J, Wood R (2000) The simulation of SST, sea ice extents and ocean heat transports in a version of the Hadley Center coupled model without flux adjustments. Clim Dyn 16:147-168

Hasselmann K (1976) Stochastic climate models, part I: theory. Tellus 28:473-485

Held I, Soden B (2006) Robust responses of the hydrological cycle to global warming. J Clim 19:5686-5699

Hirota N, Takahashi M (2012) A tripolar pattern as an internal mode of the East Asian summer monsoon. Clim Dyn. doi:10.1007/ s00382-012-1416-y

Hirota N, Takahashi M, Sato N, Kimoto M (2005) Recent climate trends in the East Asia during the Baiu season of 1979-2003. SOLA 1:137-140

Hu ZZ (1997) Interdecadal variability of summer climate over East Asia and its association with $500 \mathrm{hPa}$ height and global sea surface temperature. J Geophys Res 102:19403-19412

Huang R, Sun F (1994) Impacts of the thermal state and the convective activities in the tropical western warm pool on the summer climate anomalies in East Asia. Chin J Atmos Sci 18:141-151 in Chinese

Johns TC, Gregory JM, Ingram WJ, Johnson CE, Jones A, Lowe JA, Mitchell JFB, Roberts DL, Sexton DMH, Stevenson DS, Tett
SFB, Woodage MJ (2003) Anthropogenic climate change for 1860 to 2100 simulated with the HadCM3 model under updated emissions scenarios. Clim Dyn 20:583-612

Kusunki S, Yoshimura J, Yoshimura H, Noda A, Oouchi K, Mizuta R (2006) Change of Baiu rain band in global warming projection by an Atmospheric General Circulation Model with a $20 \mathrm{~km}$ grid size. J Meteor Soc Jpn 84:581-611

Lau K-M, Weng H (2001) Coherent modes of global sst and summer rainfall over China: an assessment of the regional impacts of the 1997-98 El Niño. J Clim 14:1294-1308

Lei Y, Hoskins B, Slingo J (2011) Exploring the interplay between natural decadal variability and anthropogenic climate change in Chinese summer rainfall. Part 1: observational evidence. J Clim 24:4584-4599

Menson S, Hanson J, Nazarenko L, Luo Y (2002) Climate effects of black carbon aerosols in China and India. Science 297:2250-2253

Monahan AH, Dai A (2004) The spatial and temporal structure of ENSO non-linearity. J Clim 17:3026-3036

Nitta T (1987) Convective activities in the tropical western Pacific and their impact on the Northern Hemisphere summer circulation. J Meteor Soc Jpn 65:373-390

North GR, Bell TL, Cahalan RF, Moeng FJ (1982) Sampling errors in the estimation of empirical orthogonal functions. Mon Wea Rev 110:699-706

Pope V, Gallani M, Rowntree P, Stratto R (2000) The impact of new physical parametrizations in the Hadley Centre climate modelHadAM3. Clim Dyn 16:123-146

Sardeshmukh PD, Hoskins BJ (1988) On the generation of global rotational flow by steady idealised tropical divergence. J Atmos Sci 45:1228-1251

Slingo J, Annamalai H (2000) The El Nino of the century and the response of the Indian summer monsoon. Mon Wea Rev 128:1778-1797

Stouffer RJ, Hegerl G, Tett S (2000) A comparison of surface air temperature variability in three 1,000-year coupled oceanatmosphere model integrations. J Clim 13:513-537

Tao SY, Chen L (1987) A review of recent research on the East Asian summer monsoon in China. In: Chang CP, Krishnamurti TN (eds) Monsoon Meteorology. Oxford University Press, Oxford, pp 60-92

Trenberth K, Hurrell W (1994) Decadal atmosphere-ocean variations in the Pacific. Clim Dyn 9:303-319

von Storch JS, Muller P, Bauer E (2001) Climate variability in millennium integrations with coupled atmosphere-ocean GCMs: a spectral view. Clim Dyn 17:375-389

Wang S, Zhao Z, Chen Z (1981) Reconstruction of the summer rainfall regime for the last 500 years in China. Geophys $\mathbf{J}$ $52: 117-122$

Wang Y, Cheng H, Edwards RL, Kong X, Shao X, Chen S, Wu J, Jiang X, Wang X, An Z (2008) Millennial- and orbital-scale changes in the East Asian monsoon over the past 224,000 years. Nature 451:1090-1093

Wang B, Liu J, Kim HJ, Webster PJ, Yim SY (2012) Recent change of the global monsoon precipitation (1979-2008). Clim Dyn 39:1123-1135

IPCC (2007) Climate Change 2007: the physical science basis. In: Slonmon S, Qin D, Manning M, Chen Z, Marquis M, Averyt KB, Tignor M, Miller HL (eds) Contribution of working group I to the fourth assessment report of the intergovernmental panel on climate change. Cambridge University Press, Cambridge

Lambert F, Gillett N, Stone D, Huntingford C (2005) Attribution studies of observed land precipitation changes with ninecoupled models. Geophys Res Lett, 32. doi:10.1029/2005GL023654

Yu R, Zhou T (2004) Impacts of winter-NAO on March cooling trends over subtropical Eurasia continent in the recent half century. Geophys Res Lett, 31. doi:10.1029/2004GRL019814 
Zhai P, Zhang X, Wan H, Pan X (2005) Trends in total precipitation and frequency of daily precipitation extremes over China. J Clim 18:1096-1108

Zhou T, Dai A (2007) The 20th century East Asian summer monsoon simulated by coupled climate models of IPCC AR4 (oral presentation) 4th international CLIVAR climate of the 20th century workshop. Hadley Centre for Climate Change, Exeter
Zhou T, Zhang L, Li H (2008) Changes in global land monsoon area and total rainfall accumulation over the last half century. Geophys Res Lett, 35. doi:10.1029/2008GRL034881

Zhu J, Wang S (2002) 80 Year oscillation of summer rainfall over North China and East Asian summer monsoon. Geophys Res Lett 14:1672. doi:10.1029/2001GL013997 